\title{
Dissolved organic matter with multi-peak fluorophores in landfill leachate
}

\author{
Fan Lu ${ }^{a, b, c}$, Cheng-Hsuan Chang ${ }^{b}$, Duu-Jong Lee ${ }^{b, *}$, Pin-Jing He ${ }^{a}$, Li-Ming Shao ${ }^{a}$, Ay Su ${ }^{c}$ \\ a State Key Laboratory of Pollution Control and Resource Reuse, Tongji University, Shanghai 200092, China \\ ${ }^{\mathrm{b}}$ Department of Chemical Engineering, National Taiwan University, Taipei 10617, Taiwan \\ ${ }^{\mathrm{c}}$ Fuel Cell Research Center, Department of Mechanical Engineering, Yuan-Ze University, Taoyuan 300, Taiwan
}

\section{A R T I C L E I N F O}

\section{Article history:}

Received 21 June 2008

Received in revised form 12 September 2008

Accepted 12 September 2008

Available online $\mathrm{xxxx}$

\section{Keywords:}

Fluorophores

Excitation and emission matrix

Size exclusion chromatography

Landfill

Leachate

\begin{abstract}
A B S T R A C T
Dissolved organic matter (DOM) sampled from municipal landfill leachate of different ages with/without anoxic or aerobic treatment, was intensively fractionated via size exclusion chromatography (SEC) and hydrophobic resins, and was studied with fluorescence excitation and emission matrix (EEM). Six fluorophores with multiple EEM peaks (fluorophore A-F) were identified based on the collected EEM spectra and validated by bi-variate analysis, principal component analysis, and parallel factor analysis, as follows (excitation wavelength Ex and emission wavelength Em): (Ex 240, 310, $360 \mathrm{~nm}$, Em $460 \mathrm{~nm}$ ), (Ex 220, 280 nm, Em 340 nm), (Ex 220, 270 nm, Em 300 nm), (Ex 220, 280 nm, Em 360 nm), (Ex 230, $320 \mathrm{~nm}$, $\mathrm{Em} 420 \mathrm{~nm}$ ) and (Ex 220, $310 \mathrm{~nm}, \mathrm{Em} 400 \mathrm{~nm})$. The spectral characteristics of these fluorophores were discussed using fractional EEM and apparent molecular weight (AMW) data obtained via SEC analysis. The triple peak flurophore A was pointed at a hydrophobic acid or hydrophobic neutral compound with a pyrenyl functional group of AMW 2500-3500 Da, which displayed an excitation wavelength at $360 \mathrm{~nm}$ and a fluorescence intensity ratio of 6.70( \pm 1.79 ): $1.70( \pm 0.41$ ): 1 (fluorescent intensities of Ex 240: $\mathrm{Ex} 310$ : Ex $360 \mathrm{~nm}$ at Ex $460 \mathrm{~nm}$ ). This compound is observed to be refractory in landfilling or in anoxic/aerobic treatments, and is specific to this leachate contamination. This paper revealed that the coupling of SEC and EEM can be useful to track the fluorescent DOM fraction in landfill leachate.
\end{abstract}

(C) 2008 Elsevier Ltd. All rights reserved.

\section{Introduction}

Fluorescence excitation and emission matrix (EEM) are used to characterize dissolved organic matter (DOM) in natural or artificial mediums, such as extracellular polymeric substances (Sheng and Yu, 2006), plant and animal biomass (Hunt and Ohno, 2007), wastewaters (Saadi et al., 2006), wetland (Maie et al., 2007), lake water (Mostofa et al., 2005), reclaimed water (Holbrook et al., 2005) and landfill leachates (Baker and Curry, 2004; Lü et al., 2008). Environmental pollutants such as polycyclic aromatic hydrocarbons (PAH) are detected and quantified using EEM (Jiji et al., 2000; Bosco et al., 2006; Nahorniak and Booksh, 2006; Reilly et al., 2006). The EEM spectra are used to quantify the degree of compound humification (Ohno, 2002; Sierra et al., 2005; Holbrook et al., 2006) or to identify the fingerprints of specific compounds in water (Baker and Curry, 2004; Wu et al., 2006). For example, the presence of EEM peaks at (Ex 250-400 nm, Em 280-380 nm) indicates the presence of anthropogenic activity in water (Baker and Curry, 2004; Coble, 2007).

Chen et al. (2003) classified EEM into five excitation-emission regions, with low emission wavelength $\operatorname{EEM}(<380 \mathrm{~nm})$ being con-

\footnotetext{
Corresponding author. Tel.: +8862 33663208; fax: +886223623040.
}

E-mail address: djlee@ntu.edu.tw (D.-J. Lee). sidered protein-origin substances, and high emission wavelength EEM (>380 $\mathrm{nm}$ ) being considered humic-like substances. Based on the scheme of Chen et al. (2003), the fractionated water samples were examined and it was generally concluded that the EEM spectra for the fractions resembled those for the un-fractionated (bulk) samples (Parlanti et al., 2002; Her et al., 2003; Sierra et al., 2006; Wang et al., 2007). However, substances such as tyrosine, phenylalanine, vitamin B2, vitamin B6, NADH and porphyrin display multiple peaks in EEM measurements, the characteristics of which are not inferred in the scheme by Chen et al. (2003).

EEM tests on experimental samples frequently displayed multiple peaks. Hua et al. (2007) observed three fluorophores with two EEM peaks from 15 observations of four water sources at (Ex 280, $370 \mathrm{~nm}, \mathrm{Em} 300 \mathrm{~nm}$ ), (Ex 230, $325 \mathrm{~nm}, \mathrm{Em} 410-430 \mathrm{~nm}$ ), and (Ex 240, 300 nm, Em 330-350 nm). Stedmon et al. (2007) identified four fluorophores with two EEM peaks from sea ice at (Ex 250, 340 nm, Em 450 nm), (Ex 250, 380 nm, Em 500 nm), (Ex 250, 310 nm, Em $400 \mathrm{~nm}$ ), and (Ex 250, $300 \mathrm{~nm}$, Em $340 \mathrm{~nm})$. Meanwhile, Hall and Kenny (2007) identified five fluorophores with multiple EEM peaks from estuarine water at (Ex 230, $300 \mathrm{~nm}, \mathrm{Em} 420 \mathrm{~nm}),(\mathrm{Ex}$ 260, $360 \mathrm{~nm}, \mathrm{Em} 470 \mathrm{~nm}$ ), (Ex 240, $340 \mathrm{~nm}, \mathrm{Em} 400 \mathrm{~nm}$ ), (Ex 230, $280 \mathrm{~nm}, \mathrm{Em} 320,600 \mathrm{~nm})$, and (Ex 220, $280 \mathrm{~nm}, \mathrm{Em} 300-600 \mathrm{~nm})$. Furthermore, Ohno and Bro (2007) identified four fluorophores with two EEM peaks from soils and soil amendment at (Ex 270, 
$350 \mathrm{~nm}, \mathrm{Em} 460 \mathrm{~nm}),(\operatorname{Ex} 250,290 \mathrm{~nm}, \mathrm{Em} 450 \mathrm{~nm}),(\operatorname{Ex} 250,310 \mathrm{~nm}$, Em $420 \mathrm{~nm}$ ), and (Ex 270, $320 \mathrm{~nm}$, Em $320 \mathrm{~nm}$ ). Moreover, Murphy et al. (2006) identified five fluorophores with multiple EEM peaks from ocean and ballast water: (Ex 260, $370 \mathrm{~nm}, \mathrm{Em} 490 \mathrm{~nm}$ ), (Ex 250, 320 nm, Em $370 \mathrm{~nm}$ ), (Ex 255, 280, 360, 410 nm, Em $580 \mathrm{~nm}$ ), $(E x<240,300 \mathrm{~nm}, E \mathrm{Em} 338 \mathrm{~nm})$, and (Ex 250, $380 \mathrm{~nm}$, Em $415 \mathrm{~nm})$. However, the above studies did not discuss the spectral characteristics of the fluorophores with these EEM peaks.

The coupling of size exclusion chromatography (SEC) and EEM can be quite useful to track the behavior of the fluorescent DOM fraction in landfill leachate. Parallel factor analysis (PARAFAC) can resolve the EEM signals of the unknown samples from that of any overlapping and uncalibrated interferents (Jiji et al., 2000). However, related SEC-EEM-PARAFAC researches are few. This work assesses the EEM spectra for DOM fractions in leachate samples obtained at a municipal landfill site. The samples for landfill of different ages and/or following anoxic storage or aerobic treatment are gathered and fractionated based on their apparent molecular weight and hydrophobicity. Bi-variate analysis, principal component analysis, and PARAFAC models identify fluorophores with multiple EEM peaks. The characteristics of these fluorophores are also addressed, and the application of the identified fluorophores for tracing leachate contamination is discussed as well.

\section{Materials and methods}

\subsection{Leachate samples and sample preparation}

Eight leachate samples (S1-S8) were obtained from different units at the Laogang Sanitary Landfill in Shanghai, China. The Laogang Landfill for municipal solid waste was constructed in four phases. Phases I $\left(1.6 \mathrm{~km}^{2}\right)$, II $\left(1.0 \mathrm{~km}^{2}\right)$, III $\left(0.82 \mathrm{~km}^{2}\right)$ and IV $\left(3.3 \mathrm{~km}^{2}\right)$ of the landfill operated since 1991, 1996, 2000 and 2005 , at daily capacities of $3000,3000,1500$ and 5000 tons of waste, respectively. S1 and S2 were sampled from two 3 month old landfill cells. Leachate sample $\mathbf{S} \mathbf{3}$ was obtained from landfill cells with ages ranging of 5-15 years. S4 was obtained from Phase III cells from landfills with ages of 3-7 years. Furthermore, S5 was obtained from Phase IV cells from landfills with ages of 1-2 years. The leachate from the Phase IV cells was stored in an anoxic pond for one month, and was then transported via a long pipe at low flow rate to an aerobic sequential batch reactor (SBR) for polishing. The leachate took approximately one month to travel through the pipe. The samples were gathered from the effluent of the anoxic pond (S6), and at the influent (S7) and effluent of the SBR (S8). Before use the sampling bottles were repeatedly cleaned using nitric acids and Milli-Q waters. The Milli-Q water stored in cleaned sampling bottles revealed no EEM peaks.

Each sampling was conducted by taking leachates at five different positions, mixed, and was stored in glass bottles at $4{ }^{\circ} \mathrm{C}$. The leachate samples were filtered through $0.45 \mu \mathrm{m}$ filter made of polypropylene (PP) housing and hydrophilic polytetrafluoroethylene (PTFE) membrane (MFS-25, Pleasanton, Calif., USA). The leachate $\mathrm{pH}$ was measured using a pH/ORP meter (OAKTON Instruments, IL, USA). The dissolved organic carbons (DOC) of the filtered leachate were measured using a TN $\mathrm{b}_{\mathrm{b}} / \mathrm{TC}$ multi N/C 3000 Analyzer (OI Analytik, Colege Station, TX, USA). The pH values of samples S1-S8 were 5.89, 5.31, 8.35, 7.80, 8.02, 7.97, 8.19 and 8.62; while their TOCs were $22300,25000,884,3480,2350,2430,1880$, and $1290 \mathrm{mg} \mathrm{L}^{-1}$, respectively. The filtrates were adjusted to $\mathrm{pH} 7$ and stored at $4{ }^{\circ} \mathrm{C}$ before the SEC-EEM and resin fractionation-EEM analysis.

\subsection{Size exclusion chromatography (SEC)}

Before SEC analysis all the leachate filtrate samples were diluted using the SEC mobile phase to DOC of $20-40 \mathrm{mg} \mathrm{L}^{-1}$ and $\mathrm{pH}$ of 6.8 .
The HPLC-SEC fractionation system was comprised of BETA 10 Gradient pump (Ecom spol. s r. o., Prague, Czech Republic), a size exclusion HW-50S column (TOYOPEARL resin with $20-40 \mu \mathrm{m}$ particle size, TOSOH Bioscience LLC, Montgomeryville, PA, USA), on-line SAPPHIRE 600 UV-vis variable wavelength detector (Ecom spol. s. r. o., Prague, Czech Republic) and IOTA 2 refractive index detector (Precision Instruments, Marseille, France), as well as a CHF 100SA fraction collector (Advantec MFS, Inc., Dublin, CA, USA). The fractions collected every three min were offline measured for fluorescence excitation and emission matrix (EEM) and dissolved organic carbon (DOC). The DOC was determined by an Aurora Model 1030 TOC Analyzer (OI Analytical, College Station, TX, USA).

The flow rate of the pump was $1 \mathrm{ml} \mathrm{min}^{-1}$. The column was employed at room temperature with a phosphate mobile phase $\left(0.0024 \mathrm{molL}^{-1} \mathrm{NaH}_{2} \mathrm{PO}_{4}+0.0016 \mathrm{molL}^{-1} \mathrm{Na}_{2} \mathrm{HPO}_{4}, \mathrm{pH} 6.8\right)$ containing $0.025 \mathrm{molL}^{-1} \mathrm{Na}_{2} \mathrm{SO}_{4}$, producing an ionic strength of $0.1 \mathrm{~mol} \mathrm{~L}^{-1}$. Polyethylene glycols (PEGs, 200, 1000, 4000, 8000 and 20000 Dalton) were used for apparent molecular weight (AMW) calibration of chromatograms. The absorption wavelength of UV detector was set at $254 \mathrm{~nm}$. UV data were collected every $0.05 \mathrm{~s}$. Two ml sample volume was injected. The SEC column presented high performance when handling three repeats for each leachate sample. The recovery rates of collected SEC effluents for $150 \mathrm{~min}$ to the inject quantity were $97-104 \%$ for S1 and S3-S6, 113\% for S2, $85 \%$ for $\mathrm{S} 7$ and $90 \%$ for S8.

\subsection{Resin fractionation}

The fractionation based on compound hydrophobicity was conducted on leachate samples following the procedures modified from Leenheer (1981). The Supelite ${ }^{\mathrm{TM}}$ DAX-8 adsorbent resin (Supelco, Sigma-Aldrich, MO, USA) was used to adsorb hydrophobic substances with different charge properties (hydrophobic neutral: HPON; hydrophobic acid: HPOA; hydrophobic base: HPOB). The modified procedure was described as follows. (1) The 0.45$\mu \mathrm{m}$ leachate filtrate (about $20 \mathrm{mg}$ DOC) was adjusted to $\mathrm{pH} 7$ with $\mathrm{NaOH}$ and $\mathrm{HCl}$ solutions and then pumped through the DAX-8 column, followed by MilliQ water. The sample effluent from the DAX-8 column was the hydrophilic fraction (HPI). (2) The hydrophobic bases (HPOB) were backflush eluted with $0.1 \mathrm{~mol} \mathrm{~L}^{-1} \mathrm{HCl}$. (3) Hydrophobic acids (HPOA) were desorbed from the DAX-8 resin by $0.1 \mathrm{~mol} \mathrm{~L}^{-1} \mathrm{NaOH}$. (4) Hydrophobic neutral fraction (HPON) was desorbed from the DAX-8 resin by $40 \%(\mathrm{v} / \mathrm{v})$ methanol. The methanol in effluent was driven out by vaccum-rotary evaporation at $35^{\circ} \mathrm{C}$. The elution or desorption curve in each step was monitored by EEM spectra, until EEM contour presented no residues.

The HPON, HPOA, HPOB and HPI fractions were adjusted to neutral $\mathrm{pH}$ with $\mathrm{NaOH}$ or $\mathrm{HCl}$ solutions, diluted with MilliQ water and then subjected to DOC and EEM analysis.

\subsection{Fluorescence excitation mission matrix (EEM)}

All samples before EEM analysis were diluted to DOC of $10 \mathrm{mg} \mathrm{L}^{-1}$ and adjusted to $\mathrm{pH}$ 7.0. Fluorescence EEM spectra of three $\mathrm{ml}$ samples were measured with a Cary Eclipse fluorescence spectrophotometer (Varian Inc., Palo Alto, CA, USA). EEM spectra were gathered with subsequent scanning emission spectra from 250 to $600 \mathrm{~nm}$ at $2 \mathrm{~nm}$ increments by varying the excitation wavelength from 200 to $500 \mathrm{~nm}$ at $10 \mathrm{~nm}$ increments. The spectra were recorded at a scan rate of $1200 \mathrm{~nm} / \mathrm{min}$, using excitation and emission slit bandwidths of $5 \mathrm{~nm}$. The fluorescent intensity corrected by emission signals to excitation power was recorded. The voltage of the photomultiplier tube (PMT) was set to $800 \mathrm{~V}$ for low level light detection. Second-order Rayleigh and Raman scattering were filtered out. The cuvettes, Milli-Q water and effluent of the mobile phase from SEC were scanned for each batch of fluorescence anal- 
ysis to avoid potential pollution during operation. The cuvettes were rinsed and ultrasonicated using $5 \%(\mathrm{w} / \mathrm{w})$ nitric acid solution before every scan.

As suggested in Baker (2001), analyses were conducted at $25 \pm 2{ }^{\circ} \mathrm{C}$, and blank water scans were performed at intervals of 5-15 analyses using Milli-Q water. The Raman peak of water at an excitation of $348 \mathrm{~nm}$ was used to test machine stability. Raman emission at $398 \mathrm{~nm}$ averaged $13.1 \pm 0.6 \mathrm{~nm}(n=50)$, and no drift was noted throughout the testing period. Optimum concentration for DOM analysis in water to minimize the inner filtering effect ranged 1-100 $\mathrm{mg} \mathrm{L}^{-1}$ (Hudson et al., 2007). In this work all samples subjected to EEM analysis were diluted to a DOC concentration
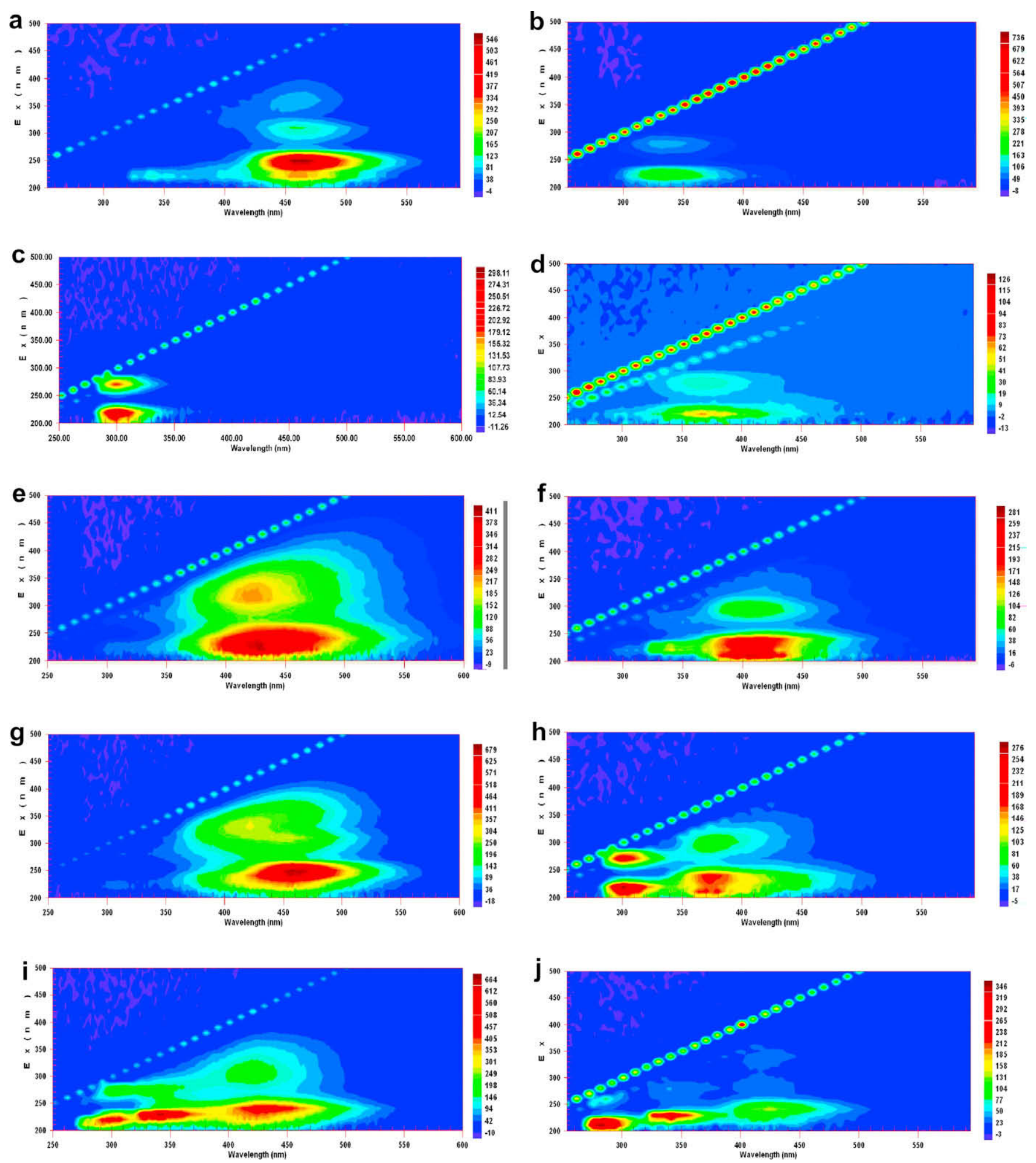

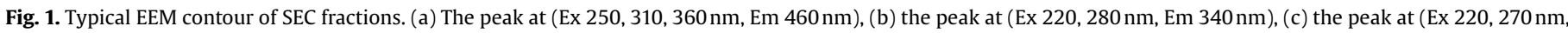

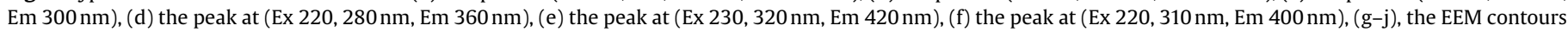
containing the peaks as presented in (a-f).

Please cite this article in press as: Lu, F. et al., Dissolved organic matter with multi-peak fluorophores in landfill leachate..., Chemosphere (2008), doi:10.1016/j.chemosphere.2008.09.060 
$<10 \mathrm{mg} \mathrm{L}^{-1}$. Dilution tests in series were conducted to confirm the removal of any inter filter effects and that the relationship between absorbance and intensity was linear. Meanwhile, a comparison was made between the uncorrected EEM spectra of diluted samples and their corrected spectra using the Raman-scatter based mathematical correction as introduced by Larsson et al. (2007). No significant difference was found between the fluorescence intensities of the corrected and uncorrected spectra.

To quantify the EEM intensity across the scan area, the intensity resulting from Rayleigh and Raman scatter was subtracted from raw spectra. The data handling of first-order Rayleigh and Raman scatter followed the protocol developed by Bahram et al. (2007) using interpolation, thus removing the interfering signal. The EEM contour was produced using Cary Eclipse Software 1.1 (Varian Inc., Palo Alto, CA, USA). Repeated tests using various pure fluorescent compounds and leachate samples demonstrated that peaks located via contoured EEM spectra presented a wavelength with maximum uncertainty of $10 \mathrm{~nm}$. This study considered two peaks with the wavelength differences of Ex $< \pm 5 \mathrm{~nm}$ and Em $< \pm 2 \mathrm{~nm}$ to be identical.

\section{Results}

\subsection{EEM peaks of leachate samples}

The EEM spectra of S1-S8 and a total of $328(=8 \times 41)$ EEM spectra of S1-S8 and their SEC fractions were collected (spectra are not shown here for brevity sake). Strong fluorescence at (Ex $220 \mathrm{~nm}, \mathrm{Em} 300 \mathrm{~nm})$ and (Ex $270 \mathrm{~nm}, \mathrm{Em} 300 \mathrm{~nm}$ ) characterized the fresh leachates (S1 and S2). The aged leachates (S3 and S4) displayed strong fluorescence at (Ex $240 \mathrm{~nm}$, Em 435-450 nm), and (Ex $310 \mathrm{~nm}$, Em $420 \mathrm{~nm}$ ). The S5 differed from S3 and S4 owing to the inclusion of an additional peak at (Ex $420 \mathrm{~nm}$, Em $470 \mathrm{~nm}$ ), which was retained in S6 and S7 following anoxic storage. The aerobic treatment removed peaks at (Ex $220 \mathrm{~nm}, \mathrm{Em} 300 \mathrm{~nm})$, (Ex $270 \mathrm{~nm}, \mathrm{Em} 300 \mathrm{~nm}$ ), and (Ex $420 \mathrm{~nm}, \mathrm{Em} 470 \mathrm{~nm}$ ), and reduced the intensities of the peaks at (Ex $230 \mathrm{~nm}, \mathrm{Em} 340 \mathrm{~nm})$ and (Ex $280 \mathrm{~nm}$, $\mathrm{Em} 360 \mathrm{~nm}$ ) in S8. No further analysis is possible owing to several overlap peaks of the collected spectra.

A total of 23 fluorescent peaks were identified by sight based on the 328 EEM spectra with peak difference $>10 \mathrm{~nm}$. Fig. 1 illustrates typical fluorescence landscapes of these EEM spectra. The positions and intensities of peaks of these fractions were listed in Fig. S1 in Supplementary material. Clear EEM peaks were observable in each fraction of the leachate samples. These peaks may be contributed by a few fluorescent compounds.

\subsection{Identification of multi-peak fluorophores}

This section identified the fluorophores with multiple EEM peaks.

The Spearman correlations coefficients for bivariate correlation analysis were calculated from the fluorescence intensities at all $23 \mathrm{Ex} / \mathrm{Em}$ positions as input variables (Table S1 in Supplementary material). Six fluorophores with multiple significantly correlated EEM peaks were observed (correlation coefficient $(r)>0.9$, significant at the 0.01 level $(p<0.01))$ : fluorophore A (Ex $250 \mathrm{~nm}, \mathrm{Em}$ $460 \mathrm{~nm}$ ), (Ex $310 \mathrm{~nm}, \operatorname{Em} 460 \mathrm{~nm})$ and (Ex $360 \mathrm{~nm}, \operatorname{Em} 460 \mathrm{~nm})$ as in Fig. 1a; fluorophore B (Ex 220 nm, Em 340 nm) and (Ex 280 nm, Em $340 \mathrm{~nm}$ ) as in Fig. 1b; fluorophore C (Ex $220 \mathrm{~nm}, \mathrm{Em} 300 \mathrm{~nm})$ and (Ex $270 \mathrm{~nm}, \mathrm{Em} 300 \mathrm{~nm}$ ) as in Fig. 1c; fluorophore D (Ex $220 \mathrm{~nm}$, Em $360 \mathrm{~nm}$ ) and (Ex $280 \mathrm{~nm}$, Em $360 \mathrm{~nm}$ ) as in Fig. 1d; fluorophore E (Ex $230 \mathrm{~nm}, \mathrm{Em} 420 \mathrm{~nm})$ and (Ex $320 \mathrm{~nm}, \mathrm{Em} 420 \mathrm{~nm})$ as in Fig. 1e; fluorophore F (Ex $220 \mathrm{~nm}, \mathrm{Em} 400 \mathrm{~nm}$ ) and (Ex $310 \mathrm{~nm}, \mathrm{Em}$ $400 \mathrm{~nm}$ ) as in Fig. 1f. Other fractional EEMs could be considered

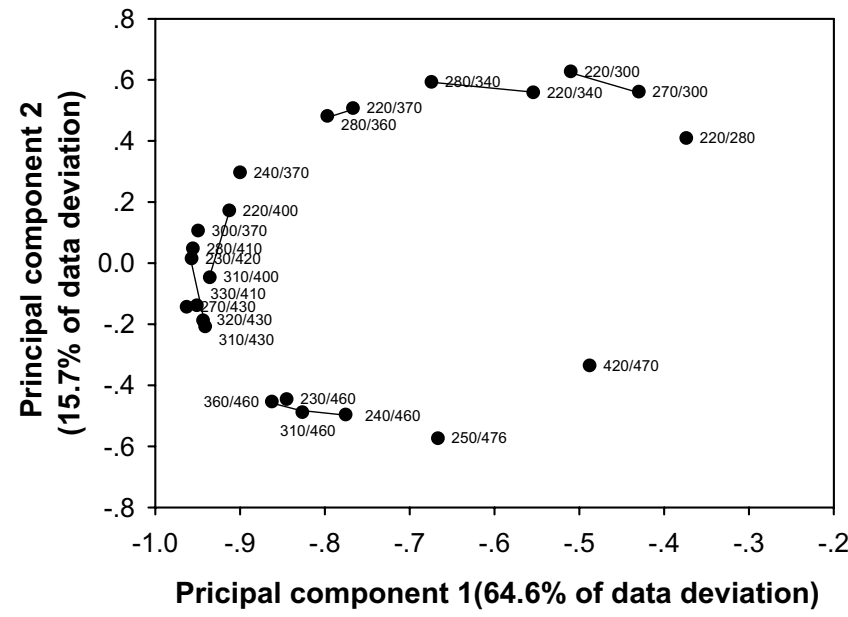

Fig. 2. Factor loading of principal component analysis. The dots connected by lines were those assumed fluorophore moieties with multi-peaks.

combinations of these fluorophores, such as EEM profiles in Fig. $1 \mathrm{~g}-\mathrm{j}$ were superimposed by peaks, as shown in Fig. 1a-f.

When adopting the fluorescence intensities of all $23 \mathrm{Ex} / \mathrm{Em}$ positions as the input variables with values centered and scaled, the principal component analysis (PCA) yielded two principal components (PC1 and PC2), comprising $64.6 \%$ and $15.7 \%$ of noted data variation, respectively. The factor loading plot (Fig. 2) revealed that the peaks were clustered based on the six multi-peak fluorophores mentioned above: the fluorophores $B-D$ on the top, the fluorophores $\mathrm{E}$ and $\mathrm{F}$ on the left, and the fluorophore $\mathrm{A}$ on the bottom. Additionally, the loading positions of some peaks with adjacent excitation and emission wavelengths clustered, indicating that these peaks were closely correlated, which may originated from the same fluorophores.

All PARAFAC analyses were performed in MATLAB 7.1 (Mathworks) using the N-way toolbox version 3.10 (Andersson and Bro, 2000). The model results were validated using core consistency diagnostic (Bro and Kiers, 2003), jack-knifing (Riu and Bro, 2003), and splithalf analysis (Andersen and Bro, 2003). The entire dataset was evaluated for outliers using the results of both identity match plots and resample influence plots (Riu and Bro, 2003). The PARAFAC model analyzed the normalized fluorescence EEM data of all $8 \times 41$ leachate SEC fractions. The core consistencies were $100 \%$, $100 \%, 99 \%, 97 \%, 82 \%, 77 \%$ and $46 \%$ for component numbers ranging from one to seven, respectively (Fig. 3a). Therefore, the optimal number of components was set to five for this model. Fig. 3b shows the corresponding excitation loading, emission loading and EEM contours of components 1-5, and the landscape of residues. Five components with characteristic peaks at fluorophores A-C, E, and (Ex 230, 260, $340 \mathrm{~nm}$, Em $460 \mathrm{~nm}$ ), respectively, were identified. The PARAFAC models for the SEC fractions of each of the samples S1-S8 were separately obtained (Table 1 ). Components from these models are closely related to the fluorophores A-F identified above.

Consequently, all three analyses (bivariate analysis, PCA, and PARAFAC) identified six mentioned fluorophores of multiple EEM peaks in the leachate samples. The following sections further discuss these six fluorophores.

\subsection{SEC and resin fractionation}

The SEC and resin fractionation and the corresponding EEM spectra demonstrated that the fluorophore A was a hydrophobic neutral (HPON) or hydrophobic acid (HPOA) compound of AMW 

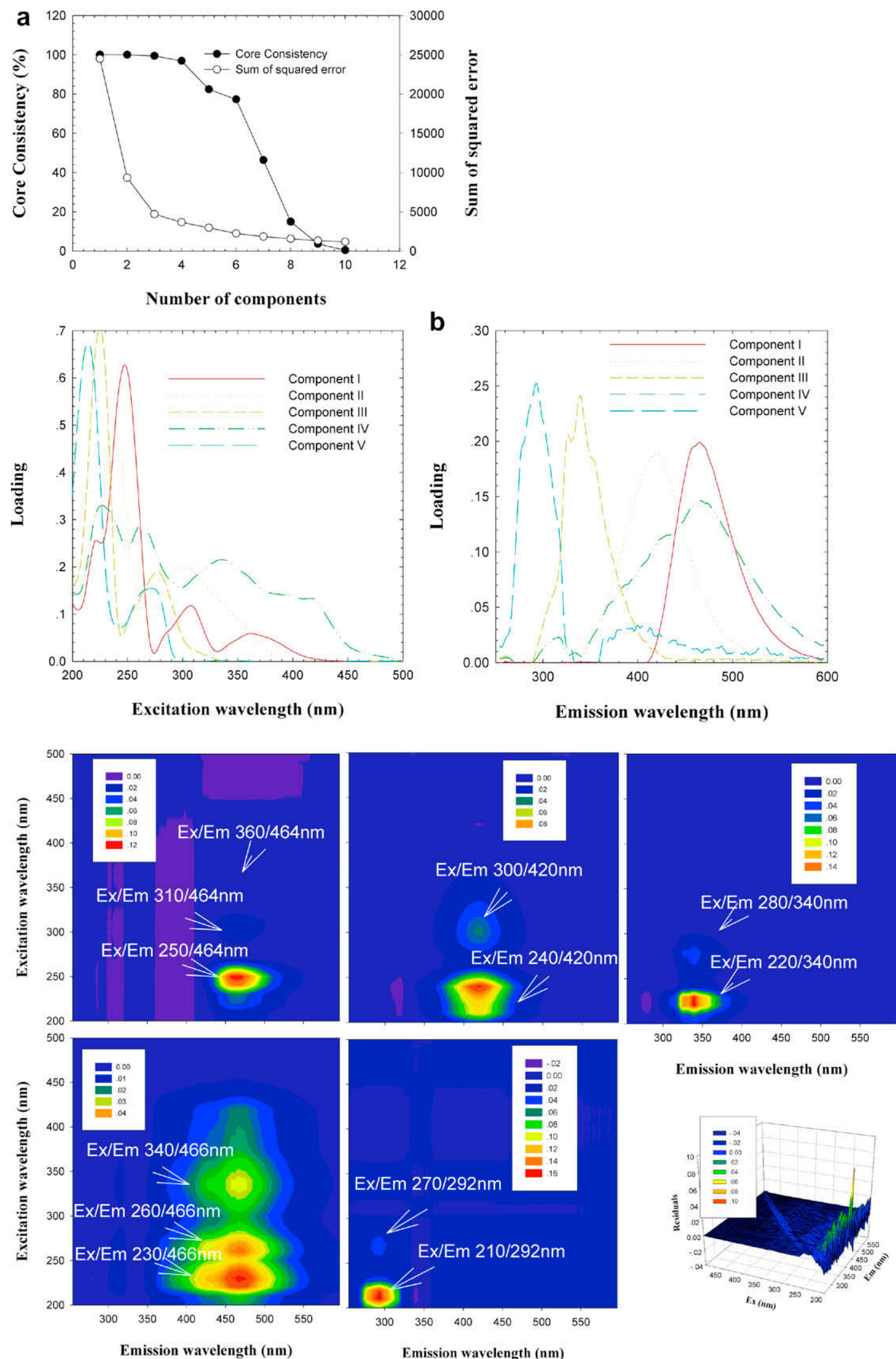

$\begin{array}{llllll}300 & 350 & 400 & 450 & 500 & 550\end{array}$

Emission wavelength (nm)

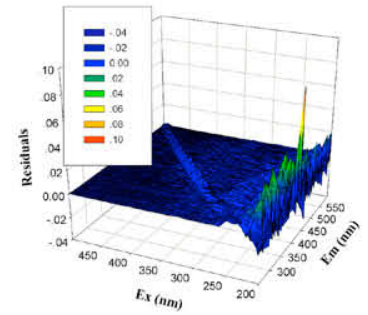

Emission wavelength (nm)

Emission wavelength (nm)

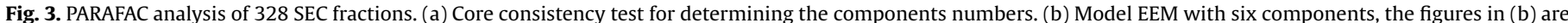
the excitation loading, emission loading, EEM contours of component 1-5, and EEM landscape of residuals.

of 2500-3500 Da. Notably, the fluorophore A with triple peaks, (Ex $250,310,360 \mathrm{~nm}, \mathrm{Em} 460 \mathrm{~nm}$ ), appeared in EEM spectra of all fractionated samples.
The fluorophore B was a hydrophobic base (HPOB) compound of AMW with 10000-30000 Da. Landfilling and aerobic treatments failed to completely remove this compound. The fluorophore $\mathrm{C}$ was 
Table 1

PARAFAC model of SEC fractions for each leachate sample

\begin{tabular}{|c|c|c|c|c|c|c|c|c|c|c|}
\hline \multirow[t]{4}{*}{ Sample } & \multirow{4}{*}{$\begin{array}{l}\text { Optimal number } \\
\text { of components }\end{array}$} & \multirow{4}{*}{$\begin{array}{l}\text { Core consis- } \\
\text { tency }(\%)\end{array}$} & \multirow{4}{*}{$\begin{array}{l}\text { Variation } \\
\text { explained (\%) }\end{array}$} & \multicolumn{7}{|c|}{ Model EEM peaks } \\
\hline & & & & \multicolumn{6}{|l|}{ Fluorophores $^{\mathrm{a}}$} & \multirow[t]{3}{*}{ Others } \\
\hline & & & & A & B & C & $\mathrm{D}$ & $\mathrm{E}$ & $\mathrm{F}$ & \\
\hline & & & & $\begin{array}{l}(\mathrm{Ex} 250,310, \\
360 \mathrm{~nm}, \mathrm{Em} \\
460 \mathrm{~nm})\end{array}$ & $\begin{array}{l}(\text { Ex 220, } \\
280 \mathrm{~nm}, \text { Em } \\
340 \mathrm{~nm})\end{array}$ & $\begin{array}{l}(\mathrm{Ex} 220, \\
270 \mathrm{~nm}, \mathrm{Em} \\
300 \mathrm{~nm})\end{array}$ & $\begin{array}{l}(\text { Ex 220, } \\
280 \mathrm{~nm}, \text { Em } \\
360 \mathrm{~nm})\end{array}$ & $\begin{array}{l}(\mathrm{Ex} 230, \\
320 \mathrm{~nm}, \mathrm{Em} \\
420 \mathrm{~nm})\end{array}$ & $\begin{array}{l}(\text { Ex 220, } \\
310 \mathrm{~nm}, \text { Em } \\
400 \mathrm{~nm})\end{array}$ & \\
\hline $\mathrm{S} 1$ & 5 & 91 & 96.00 & $10.52: 2.06: 1$ & $1.96: 1$ & $1.74: 1$ & & $2.54: 1$ & & $\begin{array}{l}(\text { Ex } 210,260 \mathrm{~nm}, \\
\text { Em } 280 \mathrm{~nm})\end{array}$ \\
\hline S2 & 4 & 94 & 92.50 & 9.09:1.84:1 & $2.38: 1$ & $2.01: 1$ & & $2.70: 1$ & & \\
\hline S3 & 4 & 88 & 97.50 & $9.27: 1.65: 1$ & $5.02: 1$ & $2.58: 1$ & & $2.01: 1$ & & \\
\hline S4 & 3 & 96 & 96.40 & $6.39: 1.29: 1$ & $2.84: 1$ & & & $2.08: 1$ & & \\
\hline S5 & 5 & 91 & 97.30 & $10.32: 2.03: 1$ & $2.26: 1$ & & & & $2.84: 1$ & $\begin{array}{l}(\text { Ex } 220,270 \mathrm{~nm} \text {, } \\
\text { Em } 340 \mathrm{~nm}) ;(\mathrm{Ex} \\
250,420 \mathrm{~nm} ; \mathrm{Em} \\
480 \mathrm{~nm})\end{array}$ \\
\hline S6 & 3 & 98 & 95.60 & 5.95:1.39:1 & 3.29:1 & & & & $2.62: 1$ & \\
\hline S7 & 5 & 89 & 98.00 & $10.82: 2.00: 1$ & $2.84: 1$ & & & & $2.74: 1$ & $\begin{array}{l}(\mathrm{Ex} 210,260 \mathrm{~nm}, \\
\mathrm{Em} 280 \mathrm{~nm}) ;(\mathrm{Ex} \\
230,340 \mathrm{~nm}, \mathrm{Em} 4 \\
70 \mathrm{~nm})\end{array}$ \\
\hline S8 & 5 & 91 & 98.60 & $10.48: 2.04: 1$ & $1.97: 1$ & $8.06: 1$ & $8.06: 1$ & $2.23: 1$ & & $\begin{array}{l}(\mathrm{Ex} 210,260 \mathrm{~nm}, \\
\text { Em280 nm) }\end{array}$ \\
\hline
\end{tabular}

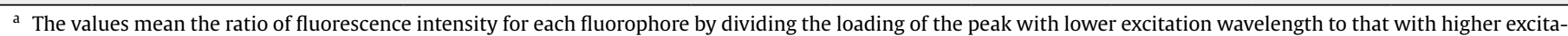
tion wavelength.

a hydrophobic base (HPOB) compound of AMW of 100-220Da. Landfilling and aerobic treatments could fully remove this compound. The fluorophore D was a hydrophobic neutral (HPON) compound of AMW of 30000-50000Da. Landfilling reduced this compound to $10000-20000 \mathrm{Da}$, and aerobic treatment fully removed the compound. The fluorophore $\mathrm{E}$ was a hydrophobic acid (HPOA) compound of AMW of 3500-5000 Da. Landfilling and aerobic treatments failed to completely remove this compound. The fluorophore F was hydrophilic (HPI) compound of AMW of 20000-50000 Da. Landfilling and aerobic treatments completely removed this compound.

Marhaba and Pu (2000) proposed that the HPOA, HPOB, and HPON fractions gathered during resin fractionation tests correspond to some part of humic substances, a soil fulvic, and a mix of hydrocarbon and carbonyl compounds, respectively. Chang (2007) observed that certain aromatic proteins can be classified as HPOB in resin fractionation.

\section{Discussion}

\subsection{Identification of fluorophores with multiple peaks}

Six fluorophores with multiple peaks were identified in the SEC fractionated leachate samples. The detected fluorescent intensities varied amongst samples. The fluorescence ratios are matrix dependent. However, in case the ratio of the fluorescent intensities for the multiple EEM peaks are identical for different measurements, the specific fluorophore can be assumed bound with a specific compound in leachate samples.

Fig. 4 illustrates the fluorescence intensity ratios of the six mentioned fluorophore of multiple EEM peaks. The intensity ratio of each fluorophore was separately calculated by dividing the intensity of the peak at lower excitation wavelength to that at higher excitation wavelength, based on the EEM data of those SEC fractions containing the targeted fluorophore. As for fluorophore A of (Ex 240, $310,360 \mathrm{~nm}$, Em $460 \mathrm{~nm}$ ), the SEC fractions containing this fluorophore have fluorescence intensity ratios of $(6.7 \pm 1.8):(1.7 \pm 0.4): 1$ for $\mathrm{Ex} / \mathrm{Em}=240 / 460,310 / 460$, and $360 / 460 \mathrm{~nm} / \mathrm{nm}$ (Fig. 1a). The

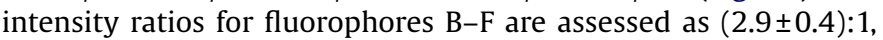

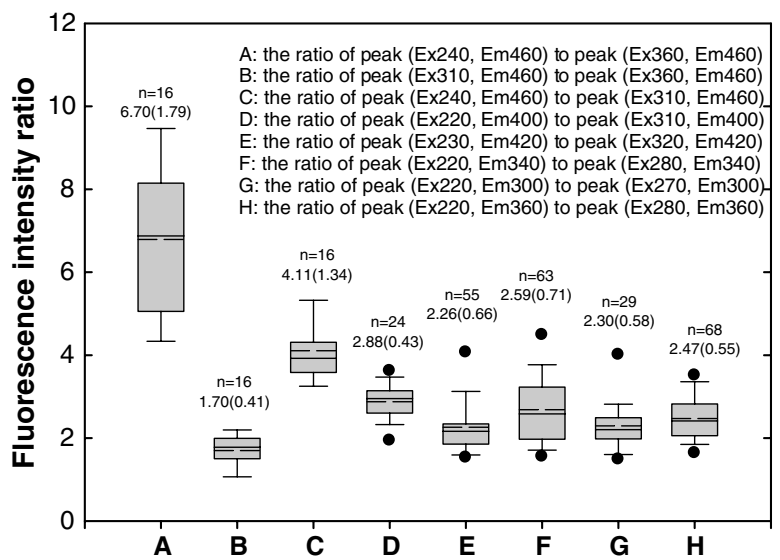

Fig. 4. Fluorescence intensity ratio of coupled peaks. The solid line within the box marks the median and the dash line marks the mean. The boundary of the box closest to zero indicates the 25th percentile, and the boundary of the box farthest from zero indicates the 75th percentile. Whiskers (error bars) above and below the box indicate the 90th and 10th percentiles. The solid circle point above and below the box indicate the 95th and 5th percentiles. $n$ is the number of the fractions calculated. The value below $\mathrm{n}$ is the mean and the standard deviation (in parentheses).

$(2.3 \pm 0.3): 1,(2.6 \pm 0.3): 1,(2.3 \pm 0.6): 1$, and $(2.4 \pm 0.1): 1$, respectively. Therefore, the ratios for each of the six fluorophores can be considered constant at a significance level of 0.05 . This observation confirms the hypothesis that the six fluorophores of multiple EEM peaks were likely associated with certain (probably six different) DOM in the leachate samples.

The fluorescence ratios calculated on the actual EEM spectra are matrix dependent. Meanwhile, the fluorescence intensity would fluctuate with interfered substances, such as fluorescence quenching by complexes of metal-ion (Plaza et al., 2006). Thereby, the matrix-independent fluorescence ratios of PARAFAC components were compared as follows and shown in Table 1. As for the fluorophore $A$, the component has fluorescence intensity ratios of $(9.2 \pm 1.9):(1.8 \pm 0.3): 1$ for $\mathrm{Ex} / \mathrm{Em}=240 / 460,310 / 460$, and $360 / 460 \mathrm{~nm} / \mathrm{nm}$. The intensity ratios for fluorophores B-F 
are assessed as (2.8 \pm 1.0$): 1,(3.6 \pm 3.0): 1,8.1: 1,(2.3 \pm 0.3): 1$, and $(2.7 \pm 0.1): 1$, respectively. It seams that the ratios of fluorophores $A$, $\mathrm{E}$ and $\mathrm{F}$ were less variable than the other three ones.

\subsection{Spectral characteristics of fluorophores with multiple EEM peaks}

Each fluorophore mentioned in Section 3.2 displays the same emission wavelength at different excitation wavelengths. This occurrence can be attributed to the rapid internal conversion of excited electrons to the lowest vibration level of the first excited state. The corresponding Stokes shift for fluorophore A is $100 \mathrm{~nm}$, closely resembling that for quinine.

Pyrene and its alkyl derivates exhibit multiple EEM peaks at (Ex 240-243, 262-272, 306-343 nm, Em 373-398 nm) (Zimerman and Weiss, 1999). Engst et al. (1999) found that 1-methylpyrene and 1-ethylpyrene displayed three excitation peaks, at 241-242, 261281 and $325-352 \mathrm{~nm}$. The excitation wavelength of fluorophore A was similar to that of abovementioned pyrene family, whereas the emission wavelength of fluorophore A (460-470 nm) differed from that of pyrene family ( $373-417 \mathrm{~nm}$ in ethanol), possibly contributing to the excimeric emission of pyrene (Cheng et al., 2006). Fluorophore A was characterized in HPON or HPOA fractions by resins. It suggested fluorophore A derived from a hydrophobic compound containing pyrenyl functional group of MW 2500-3500 Da. It was noteworthy that the fluorophore A compound could not be significantly removed by landfill aging or anoxic/aerobic treatments. However, it was difficult to determine whether this fluorophore pertained to DOM or a closely related xenobiotic compound, since natural humic substances contained aromatic domains.

The fluorescent fluorophore B exhibited EEM peaks resembling those for tryptophan (Du et al., 1998; Pitts et al., 2001), and was characterized in the HPOB fraction using resin. Consequently, the fluorophore $B$ is suggested to be a tryptophan-like substance of AMW 10000-30000 Da. However, naphthalene moieties also displayed the characteristic fluorescence spectra of excitation wavelength 220-260 nm, monomeric emission of approximately $335 \mathrm{~nm}$ (Beltrán et al., 1998; Baker and Curry, 2004), creating another candidate for the fluorophore $\mathrm{B}$ compound.

The fluorescent fluorophore $C$ had EEM peaks resembling tyrosine (Teale and Weber, 1957), and was characterized in HPOB fraction by resin. The fluorescent fluorophore $C$ is suggested to be a tyrosine-side substance of AMW 100-220Da. Phenylalanine is another candidate which contained 2-coupled peaks of excitation wavelength at 206 and $257 \mathrm{~nm}$ and an emission wavelength at $280 \mathrm{~nm}$ (Saidel et al., 1952; Teale and Weber, 1957).

The peaks of fluorophore $\mathrm{D}$ resembled those of fluorophore $\mathrm{B}$ with red shift. Since the fluorophore D was classified as HPON using resin, and since a close correspondence was observed between the trypophan and fulvic acid-like substances in the PCA analysis (Fig. 2 ), the fluorophore D may be related to microbial formed fulvic acid-like substance by a long aliphatic chain.

The fluorescent fluorophore E seemed to be related to humic substances of AMW 3500-5000 Da, on the basis of the EEM peaks and the HPOA characteristics. Corresponding to this fluorophore, Sun et al. (2007) identified two peaks as displaying sediment humic substances, including a strong peak at (Ex $310-330 \mathrm{~nm}$, Em 390-400 nm), and a less intense but more variable peak at (Ex 250-260 nm) and Em 400-450 nm. Chen et al. (2003) identified two EEM peaks at (Ex 210-230, 300-350 nm, Em 400-430 nm) in the hydrophilic acid fraction of the Salt River, hydrophobic acid fraction of the Gila River, the basic fraction of the effluent from wastewater treatment plant, and biomass from wastewater treatment plants.

The fluorescent fluorophore $\mathrm{F}$ displayed EEM characteristics of humic substance, although it was characterized as comprising hydrophilic compounds by resins and was rarely clearly identified in the bulk samples. Coble (2007) observed that the fluorophore of (Ex 290-310 nm, Em 370-410 nm) should comprise humic-like, anthropogenic substances from wastewater and agriculture.

\subsection{Leachate characteristics}

Fluorophores D-F correlate with the humic substances while fluorophores B-C correlate with the proteins (Chen et al., 2003). The EEM peaks of the fluorophores B-F overlapped considerably with EEM tests described in the literature with environmental samples. Additionally, fluorophores C, D and F are compounds that are completely degraded during landfilling and/or aerobic treatment. Consequently, although Baker and Curry (2004) observed intense fluorescence at (Ex 220-230 nm, Em 340-370 nm) in all tested landfill leachates and suggested the fluorescence derived from fluorescent xenobiotic organic matter such as naphthalene, the suggestion cannot be applied to the present studied landfill.

Conversely, the fluorescent fluorophore A with three coupled peaks (Ex $250 \mathrm{~nm}, \mathrm{Em} 460 \mathrm{~nm}),(\mathrm{Ex} 310 \mathrm{~nm}, \mathrm{Em} 460 \mathrm{~nm})$ and (Ex $360 \mathrm{~nm}$, Em $460 \mathrm{~nm}$ ) was demonstrated to be refractory in all leachate samples (Fig. 3) regardless of landfill age and anoxic/ aerobic treatments. Restated, this refractory organic matter was strongly associated with the investigated landfill leachates. The hydrophobic nature of the fluorophore A makes it easily concentrated using hydrophobic resins, and its intermediate AMW of 2500-3500 Da makes it suitable for fractionation using SEC. Additionally, its three-peak characteristics with intensity ratios $6.70( \pm 1.79): 1.70( \pm 0.41): 1$ are rare in samples from the literature. Whether this fluorophore could be employed as a tracer to identify pollutants from the studied landfill leachate is under investigation.

Fluorescence spectrographic methods are used for characterizing leachate DOM and other environmental samples (Marhaba et al., 2000; Her et al., 2003; Baker and Curry, 2004; Sierra et al., 2006; Hua et al., 2007). By applying different chemometric analyses, and especially using the PARAFAC analysis, the present study validated that pairs of dependent peaks should pertain to at least six fluorophore compounds. Especially, the compound with triple fluorescence peaks was observed to be refractory in landfilling or in anoxic/aerobic treatments, and was specific to this leachate contamination. This paper revealed that the coupling of SEC and EEM can be useful to track the fluorescent DOM fraction in landfill leachate.

\section{Acknowledgements}

The work was financially supported by the National Natural Science Foundation of China (50708069, 50538080, 50578115), the National High-Tech Research and Development Program (2003AA644020), Specialized Research Fund for the Doctoral Program of Higher Education of China (20070247009) and Shanghai Educational Development Foundation (2007CG25). Lü Fan joined Yuan Ze University as a postdoctor fellow during February-June, 2007.

\section{Appendix A. Supplementary material}

Figure and Table showing the peak location ands intensities, and the associated bivariate analysis. Supplementary material associated with this article can be found, in the online version, at doi:10.1016/j.chemosphere.2008.09.060.

\section{References}

Andersson, C.A., Bro, R., 2000. The n-way toolbox for MATLAB. Chemometr. Intell. Lab. 52, 1-4. 
Bahram, M., Bro, R., Stedmon, C., Afkhami, A., 2007. Handling of Rayleigh and Raman scatter for PARAFAC modeling of fluorescence data using interpolation. J. Chemom. 20, 99-105.

Baker, A., 2001. Fluorescence excitation-emission matrix characterization of some sewage-impacted rivers. Environ. Sci. Technol. 35, 948-953.

Baker, A., Curry, M., 2004. Fluorescence of leachates from three contrasting landfills. Water Res. 38, 2605-2613.

Beltrán, J.L., Ferrer, R., Guiteras, J., 1998. Multivariate calibration of polycyclic aromatic hydrocarbon mixtures from excitation-emission fluorescence spectra. Anal. Chim. Acta 373, 311-319.

Bosco, M.V., Callao, M.P., Larrechi, M.S., 2006. Simultaneous analysis of the photocatalytic degradation of polycyclic aromatic hydrocarbons using three-dimensional excitation-emission matrix fluorescence and parallel factor analysis. Anal. Chim. Acta 576, 184-191.

Bro, R., Kiers, H.A.L., 2003. A new efficient method for determining the number of components in PARAFAC models. J. Chemom. 17, 274-286.

Chang, C.H., 2007. Fractionation of dissolved organic matters in waters. MS thesis, National Taiwan University.

Chen, W., Westerhoff, P., Leenheer, J.A., Booksh, K., 2003. Fluorescence excitationemission matrix regional integration to quantify spectra for dissolved organic matter. Environ. Sci. Technol. 37, 5701-5710.

Cheng, K., Schepp, N.P., Cozens, F.L., 2006. Resolution of ultrafast pyrene excimer emission rise times in zeolites X and Y. Photochem. Photobiol. 82, 132-138.

Coble, P.G., 2007. Marine optical biogeochemistry: the chemistry of ocean color. Chem. Rev. 107, 402-418.

Du, H., Fuh, R.C.A., Li, J.Z., Corkan, L.A., Lindsey, J.S., 1998. PhotochemCAD: a computer-aided design and research tool in photochemistry. Photochem. Photobiol. $68,141-142$.

Engst, W., Landsiedel, R., Hermersdorfer, H., Doehmer, J., Glatt, H., 1999. Benzylic hydroxylation of 1-methylpyrene and 1-ethylpyrene by human and rat cytochromes P450 individually expressed in V79 Chinese hamster cells. Carcinogenesis 20, 1777-1785.

Hall, G.J., Kenny, J.E., 2007. Estuarine water classification using EEM spectroscopy and PARAFAC-SIMCA. Anal. Chim. Acta 581, 118-124.

Her, N., Amy, G., McKnight, D., Sohn, J., Yoon, Y., 2003. Characterization of DOM as a function of MW by fluorescence EEM and HPLC-SEC using UVA, DOC, and fluorescence detection. Water Res. 37, 4295-4303.

Holbrook, R.D., Breidenich, J., DeRose, P.C., 2005. Impact of reclaimed water on select organic matter properties of a receiving stream-fluorescence and perylene sorption behavior. Environ. Sci. Technol. 39, 6453-6460.

Holbrook, R.D., DeRose, P.C., Leigh, S.D., Rukhin, A.L., Heckert, N.A., 2006. Excitation-emission matrix fluorescence spectroscopy for natural organic matter characterization: a quantitative evaluation of calibration and spectral correction procedures. Appl. Spectr. 60, 791-799.

Hua, B., Dolan, F., McGhee, C., Clevenger, T.E., Deng, B.L., 2007. Water-source characterization and classification with fluorescence EEM spectroscopy: PARAFAC analysis. Int. J. Environ. Anal. Chem. 87, 135-147.

Hudson, N., Baker, A., Reynolds, D., 2007. Fluorescence analysis of dissolved organic matter in natural, waste and polluted waters - A review. River Res. Appl. 23, 631-649.

Hunt, J.F., Ohno, T., 2007. Characterization of fresh and decomposed dissolved organic matter using excitation-emission matrix fluorescence spectroscopy and multiway analysis. J. Agri. Food Chem. 55, 2121-2128.

Jiji, R.D., Andersson, G.G., Booksh, K.S., 2000. Application of PARAFAC for calibration with excitation-emission matrix fluorescence spectra of three classes of environmental pollutants. J. Chemom. 14, 171-185.

Larsson, T., Wedborg, M., Turner, D., 2007. Correction of inner-filter effect in fluorescence excitation-emission matrix spectrometry using Raman scatter. Analytica Chim. Acta 583, 357-363.

Leenheer, J.A., 1981. Comprehensive Approach to preparative isolation and fractionation of dissolved organic-carbon from natural-waters and wastewaters. Environ. Sci. Technol. 15, 578-587.

Lü, F., Zhang, H., Chang, C.H., Lee, D.J., He, P.J., Shao, L.M., Su, A., 2008. Dissolved organic matter and estrogenic potential of landfill leachate. Chemosphere 72 , 1381-1386.

Maie, N., Scully, N.M., Pisani, O., Jaffe, R., 2007. Composition of a protein-like fluorophore of dissolved organic matter in coastal wetland and estuarine ecosystems. Water Res. 41, 563-570.
Marhaba, T.F., Pu, Y., 2000. Rapid delineation of humic and non-humic organic matter fractions in water. J. Haz. Mat. 73, 221-234.

Marhaba, T.F., Van, D., Lippincott, R.L., 2000. Rapid identification of dissolved organic matter fractions in water by spectral fluorescent signatures. Water Res. 34, 3543-3550.

Mostofa, K.M.G., Yoshioka, T., Konohira, E., Tanoue, E., Hayakawa, K., Takahashi, M., 2005. Three-dimensional fluorescence as a tool for investigating the dynamics of dissolved organic matter in the Lake Biwa watershed. Limnology 6, 101-115.

Murphy, K.R., Ruiz, G.M., Dunsmuir, W.T.M., Waite, T.D., 2006. Optimized parameters for fluorescence-based verification of ballast water exchange by ships. Environ. Sci. Technol. 40, 2357-2362.

Nahorniak, M.L., Booksh, K.S., 2006. Excitation-emission matrix fluorescence spectroscopy in conjunction with multiway analysis for PAH detection in complex matrices. The Analyst 131, 1308-1315.

Ohno, T., 2002. Fluorescence inner-filtering correction for determining the humification index of dissolved organic matter. Environ. Sci. Technol. 36, 742-746.

Ohno, T., Bro, R., 2007. Dissolved organic matter characterization using multiway spectral decomposition of fluorescence landscapes. Soil Sci. Soc. Am. J. 70, 2028-2037.

Parlanti, E., Morin, B., Vacher, L., 2002. Combined 3 D-spectrofluorometry, high performance liquid chromatography and capillary electrophoresis for the characterization of dissolved organic matter in natural waters. Org. Geochem. 33, 221-236

Pitts, J.D., Sloboda, R.D., Dragnev, K.H., Dmitrovsky, E., Mycek, M.A., 2001. Autofluorescence characteristics of immortalized and carcinogen-transformed human bronchial epithelial cells. J. Biomed. Opt. 6, 31-40.

Plaza, C., Brunetti, G., Senesi, N., Polo, A., 2006. Fluorescence characterization of metal ion-humic acid interactions in soils amended with composted municipal solid wastes. Analyt. Bioanalyt. Chem. 386, 2133-2140.

Reilly, N.J., Schmidt, T.W., Kable, S.H., 2006. Two-dimensional fluorescence (excitation/emission) spectroscopy as a probe of complex chemical environments. J. Phys. Chem. A 110, 12355-12359.

Riu, J., Bro, R., 2003. Jack-knife technique for outlier detection and estimation of standard errors in PARAFAC models. Chemometr. Intell. Lab. 65, 35-49.

Saadi, I., Borisover, M., Armon, R., Laor, Y., 2006. Monitoring of effluent DOM biodegradation using fluorescence, UV and DOC measurements. Chemosphere 63 530-539.

Saidel, L.J., Goldfarb, A.R., Waldman, S., 1952. The absorption spectra of amino acids in the region two hundred to two hundred and thirty millimicrons. J. Biol. Chem. 197, 285-291.

Sheng, G.P., Yu, H.Q., 2006. Characterization of extracellular polymeric substances of aerobic and anaerobic sludge using three-dimensional excitation and emission matrix fluorescence spectroscopy. Water Res. 40, 1233-1239.

Sierra, M.M.D., Giovanela, M., Parlanti, E., Soriano-Sierra, E.J., 2005. Fluores cence fingerprint of fulvic and humic acids from varied origins as viewed by single-scan and excitation/emission matrix techniques. Chemosphere 58 $715-733$.

Sierra, M.M.D., Giovanela, M., Parlanti, E., Soriano-Sierra, E.J., 2006. 3D-fluorescence spectroscopic analysis of HPLC fractionated estuarine fulvic and humic acids. J. Brazilian Chem. Soc. 17, 113-124.

Stedmon, C.A., Thomas, D.N., Granskog, M., Kaartokallio, H., Papadimitriou, S. Kuosa, H., 2007. Characteristics of dissolved organic matter in Baltic coastal sea ice. Allochthonous or autochthonous origins? Environ. Sci. Technol. 41, 7273-7279.

Sun, W.L., Ni, J.R., Xu, N., Sun, L.Y., 2007. Fluorescence of sediment humic substance and its effect on the sorption of selected endocrine disruptors. Chemosphere 66, 700-707.

Teale, F.W.J., Weber, G., 1957. Ultraviolet fluorescence of amino acids. Biochem. J 65, 476-482.

Wang, L.S., Hu, H.Y., Wang, C., 2007. Effect of ammonia nitrogen and dissolved organic matter fractions on the genotoxicity of wastewater effluent during chlorine disinfection. Environ. Sci. Technol. 41, 160-165.

Wu, J., Pons, M.N., Potier, O., 2006. Wastewater fingerprinting by UV-visible and synchronous fluorescence spectroscopy. Water Sci. Technol. 53, 449-456.

Zimerman, O.E., Weiss, R.G., 1999. Pyrene photochemistry in solid n-alkane matrices: comparisons with liquid-phase reactions. J. Phys. Chem. A 103, 97949804. 